\title{
ENTREPRENEURIAL ORIENTATION IN A \\ SITUATIONAL CONTEXT: COMPARISONS BETWEEN \\ GERMANY AND THE UNITED STATES
}

\author{
Darla Domke-Damonte \\ Coastal Carolina University \\ Conway, SC \\ Jens Andreas Faulstich \\ RheinAhr Campus, Remagen \\ Fachhochschule Koblenz \\ Remagen, Germany
}

William Woodson III

\begin{abstract}
Previous research has evaluated some elements of U.S. students 'entrepreneurial orientation, while the present research extends and broadens this research to consider different situational settings across students in both Germany ( $n=$ 95) and the United States $(n=147)$. The study evaluates both self-perceptions of entrepreneurial orientation and perceptions of the average level of entrepreneurial orientation of the country in which the student resides, based on parental involvement and the different economic and social conditions within which the siudent resides. Results indicate that parental entrepreneurship and country of origin affect self-perception of entrepreneurial orientation, but that only country of origin affects perceptions of one's countrymen's entrepreneurial orientation.
\end{abstract}

Entrepreneurial orientation provides an indicator of the requisite behavioral initiatives that are conducive to new venture development (Lumpkin \& Dess, 1996) and insight into the predispositions that an individual may carry with him or her into a business setting (Grant \& Bush, 1995; West, Bamford, \& Marsden, 2008). However, limited attention has been given to the evaluation of an individual's self-perceptions of his or her entrepreneurial orientation and how that evaluation may differ by the social and economic background of the country in which the individual was socialized. The present paper attempts to integrate an explanation of the effects of social and economic issues on self-perception of entrepreneurial orientation. The paper begins by providing a basic literature review and overview of its major hypotheses, the methods used to collect the data are described along with the process used to evaluate the data, and finally results are presented along with a discussion of the outcomes of the process. 


\section{Figure 1}

\section{Research Model: Effects of Social and Economic Conditions on Perceptions of Entrepreneurial Orientation}

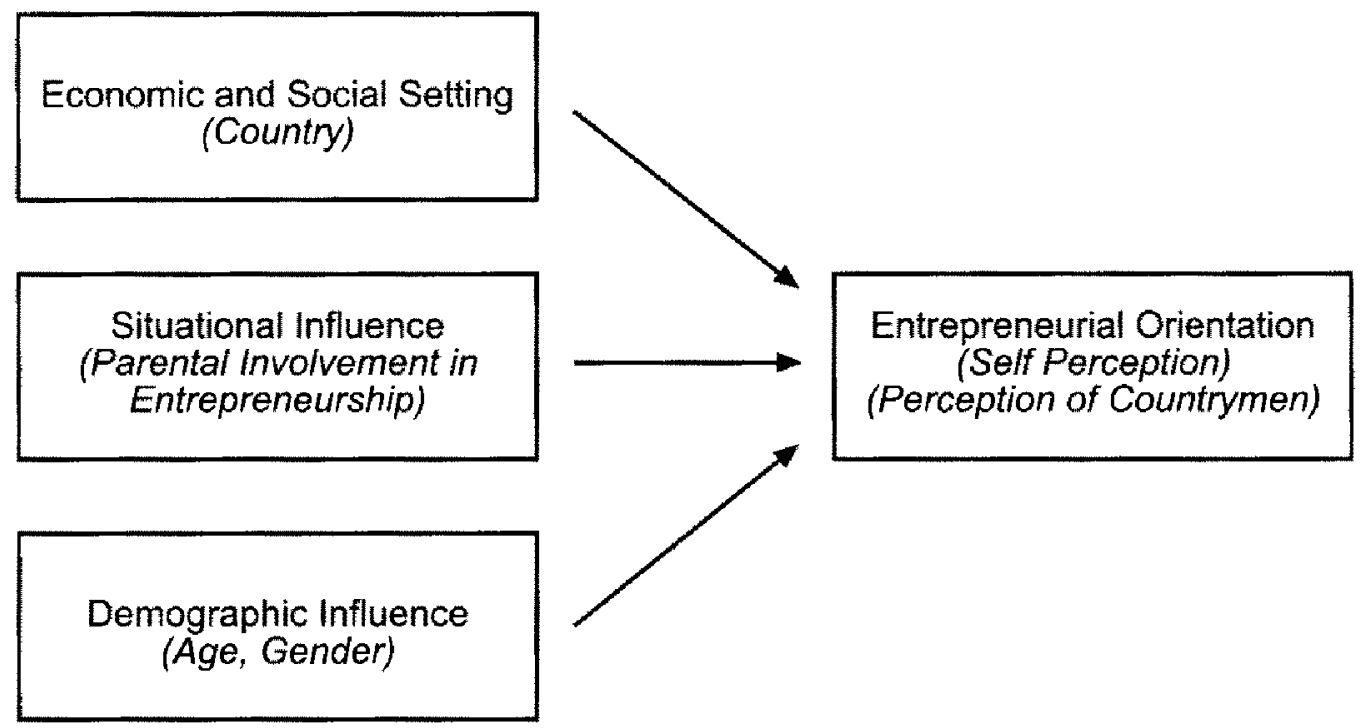

\section{Literature Review and Hypothesis Development}

Lumpkin and Dess (1996: 136-137) note that entrepreneurial orientation (EO) "involves the intentions and actions of key players functioning in a dynamic generative process aimed at new venture creation....The key dimensions that characterize an entrepreneurial orientation include a propensity to act autonomously, a willingness to innovate and take risks, and a tendency to be aggressive toward competitors and proactive relative to marketplace opportunities." Miller (1983) noted that competitive aggressiveness was a strong component of entrepreneurial orientation, and Burgelman (1983) noted that independent action and autonomy were critical elements of internal corporate venturing behavior.

The present research attempts to formulate a clearer understanding of some of the precursors to individuals' own perceptions of entrepreneurial orientation. As shown in Figure 1, the research model attempts to link the economic and social setting within which an individual grows up to his or her own perceptions of entrepreneurial orientation. In addition, the model recognizes and builds on prior work that indicates that situational factors, such as role models in entrepreneurial activity, and demographic factors also may affect entrepreneurial orientation. The following paragraphs further delineate the constructs under study, provide background on the research supporting the model's proposed relationships, and develop specific hypotheses which are tested in the research.

A core challenge with the previous conceptualization of much of the work on entrepreneurial orientation is that it is linked only to the top management team level, or to the organizational level and not to the individual level of analysis. 
To formalize the measurement of the construct of entrepreneurial orientation, a variety of scales have been developed. Lyon, Lumpkin, and Dess (2000) note numerous ways to measure the construct, but point out that it may be an artifact of the individual respondent, rather than a firm-level construct. Miller (1983) developed a scale to assess the EO construct which Covin and Slevin (1989) expanded. However, numerous challenges have been posed with these instruments, based on the combination of both present and past behaviors. Moreover, these scales were developed to assess firm-level entrepreneurship, while our intention in the present paper was to measure entrepreneurial orientation of future potential business owners. As Bird (1988) noted, entrepreneurial intention is the precursor to entrepreneurial activity and it is in this direction that the current research is directed as clearly the initiative and interest must exist before the action of starting a business will proceed. Grant and Bush (1995) noted that "these scales assess an organization's business orientation rather than an employee's psychological orientation or propensity to act in an entrepreneurial manner." As a result, they developed and validated a scale to measure entrepreneurial orientation (EO) among individual salespeople.

The approach taken by Grant and Bush (1995) is unique from other conceptualizations, which focus on the domain of entrepreneurial orientation on the top management team (Morris \& Paul, 1987; Lyon, Lumpkin, \& Dess, 2000; Lumpkin \& Dess, 1996; Hughes \& Morgan, 2007; Avlonitis \& Salavou, 2007, among others). Grant and Bush (1995) allow for the notion that entrepreneurial orientation may be noted at any level of an organization, because it may not be viewed just as a strategic orientation of top managers, but rather as a psychological disposition to acting within any organizational environment.

This distinction is critical to the present argument, because it suggests that individuals arrive into an institutional setting with a comfort zone of how they will approach risk taking, innovation, acting autonomously, and proactively initiating action on the part of the firm. As Grant and Bush (1995) note, it is more likely that these attitudes develop from childhood experiences. Generational effects that condition behaviors starting in young and early adulthood (Baumeister \& Muraven, 1996) may condition individuals to perceive the social environment around them in ways that either encourage or discourage innovation and risk taking behavior. Belief systems theory (Rokeach, 1973) also notes that as long as the individual is relatively happy with his or her own self-concept and self-presentation to others, the value systems and perceptions that have been adopted will remain stable. Self-concept may be both oriented toward one's own role within society and also may be used to gauge the perception of the society from an insider's perspective. This perception of the level of entrepreneurial activity of one's own society may be instructive as it should also condition the potential pursuit of future activity, according to belief systems theory (Rokeach, 1973). Therefore, to fully understand an individual's self-perception of entrepreneurial orientation as well as their perception of their countrymen's level of entrepreneurial orientation, it is clearly 
important to consider the ways in which social forces may affect differences in entrepreneurial orientations.

Gender has long been suggested to be tied to risk taking behavior and career choice. Jiankoplos and Bernasek (1998) note that women are more risk averse in financial risk taking, while Hersch (1996) noted more conservative consumer decision making practices. Parks-Yancy, DiTomaso, and Post (2005) demonstrate that women have lower access to social capital resources than do men, and Brush (1997) noted that women experience important cultural and situational barriers to entrepreneurship. Langowitz, Sharpe, and Godwin (2006) note that women face significant levels of challenge with respect to establishing new businesses, including their own perception of their ability to be successful, and Grant (1996) found that women had lower entrepreneurial intentions. Furthermore, the importance of social capital to successful startup of new ventures has been established by Davidsson and Honig (2003), and that networks (Aldrich \& Martinez, 2001) and role models (Wagner \& Sternberg, 2004) are important for successful startup. Langowitz, et al. (2006) note that there is a strong increase in the support available to women entrepreneurs in the U.S. has increased over the last few decades especially since the passage of HR 5050, which was also known as the Women's Business Ownership Act of 1988. Despite the larger number of role models of female entrepreneurs evident than in the past, with 5.4 million businesses generating $\$ 819$ billion in revenues owned by women in 1997 in the United States (Small Business Administration, 2003), it is anticipated that women's self-perceptions of entrepreneurial orientation will be lower than men's. In addition, because self-perception may also be linked to inference of the level of entrepreneurial orientation of others, it is also likely that perceptions of countrymen's entrepreneurial orientation will differ by gender (Rokeach, 1973). Thus, the following hypothesis is proposed:

Hypothesis 1: Gender will be correlated with both self-perceptions of entrepreneurial orientation and perceptions of entrepreneurial orientation of fellow countrymen, with males scoring higher in both areas than women.

In addition, it is not unreasonable to expect that those who have a parent who is involved with his or her own business will have higher entrepreneurial orientation because they will more likely understand the demands that it places on risk taking, innovation, and being proactive within the competitive environment. Previous research (Krueger 1993; Scott \& Twomey, 1988, Grant, 1996) has found that those with parents who have their own businesses are more likely to have an interest or to be planning to be involved in entrepreneurial activity. Moreover, Van Lange, De Bruin, Otten, and Joireman (1997) suggested that basic value orientations are partly linked to the types of social interactions engaged in during early childhood to early adulthood and further influenced by the social interactions and experiences encountered during adulthood. As these students will have perceived their 
parents to have the role of risk taker, innovator, and proactive business leader, it is expected that they will be more likely to generalize this perception to their fellow countrymen. As noted by Aldrich and Martinez (2001) and Wagner and Sternberg (2004), role models and networks are critical to entrepreneurial activity, and the networks that these individuals see as a normal part of their parent's or parents' business environment as entrepreneurs may contribute to their believing that all of their countrymen have similar circumstances. Thus, the following hypothesis is proposed:

Hypothesis 2: Individuals who have parents who operate their own businesses will have greater perceptions of their own entrepreneurial orientation and higher perceptions of their countrymen's average level of entrepreneurial orientation.

Finally, social settings may also influence self-perceptions of entrepreneurial orientation and of the level of entrepreneurial orientation of one's countrymen. Modernization theory (c.f., Inglehart \& Baker, 2000; Gundelach, 1994) suggests that scarcity in social and economic resources provide strong influences on the creation of initial value systems for young preadults, by enabling increasing opportunities and reinterpretation of existing social norms during periods of economic and social growth and prosperity, and by requiring a curtailed focus on survival needs during times of economic scarcity and social pressures (Inglehart \& Baker, 2000 ). Changes in the basic social institutions in various countries have made the process of growing up different for youth over the last fifty years (Trump, 1991). Baumeister and Muraven (1996: 406) suggest that there has been "an immense loosening of societal guidelines, restrictions, and pressures, allowing people an almost unprecedented degree of freedom." This freedom has placed additional pressures on individuals to create their own identity, and this pressure is particularly acute during adolescent years (Gundelach, 1994). Moreover, the increasing range of potential career opportunities available and increases in educational availability to students from more disparate economic backgrounds and genders have made the choice of one's identity broaden from the list available to those in earlier generations. Trump (1991:367) notes that Inglehart's modernization theory suggests "environmental conditions in existence when one is growing up are seen as crucial in determining the psychological need level at which one fixates, and therefore the type of values one holds most dear." In support of this view, Bloodgood, Sapienza, and Carsrud (1995) note that factors such as community, government agencies, financial resources, and family issues all may affect entrepreneurial activity as well. To consider this effect requires that one evaluate the different social settings in which these students have grown up as Lee and Peterson (2000: 403) noted 'individuals' personalities, and behaviors, firms, political legal systems, economic conditions, and social mores are all intertwined with the national culture from which they originate." It is further appropriate to consider the effects of such social and economic conditions on what individuals 
within the respective country think about the level of entrepreneurial orientation of their countrymen because these perceptions may also frame a different dimension to the readiness to actually engage in entrepreneurial activity.

As one seeks to understand whether social and economic conditions contribute to perceptions of entrepreneurial orientation, it seems appropriate to first test whether such differences existed in two well developed nations that are more similar to one another culturally. In their qualitative study, Lee-Ross and Mitchell (2007) found that prevailing economic conditions make for very different conditions and possibilities for entrepreneurs and noted significant divergence from western models. As such, our assumption was that if such differences existed between individuals within two well developed nations, then there was justification in exploring differences in social settings that were even more diverse. Given that Germany and the United States score relatively closely to one another on several of Hofstede's (2001) dimensions, with the only large difference that of the U.S. being much higher on individualism than Germany and a moderate difference in uncertainty avoidance with Germany higher on uncertainty avoidance that the United States, this study sought to explore differences in perceptions of entrepreneurial orientation between the United States and Germany. The following section provides a snapshot of the differing economic and social evolutions in the U.S. and Germany over the last two decades.

Figure 2

New Business Start Ups of Firms with Employees in Germany and the United States, 1990-2002

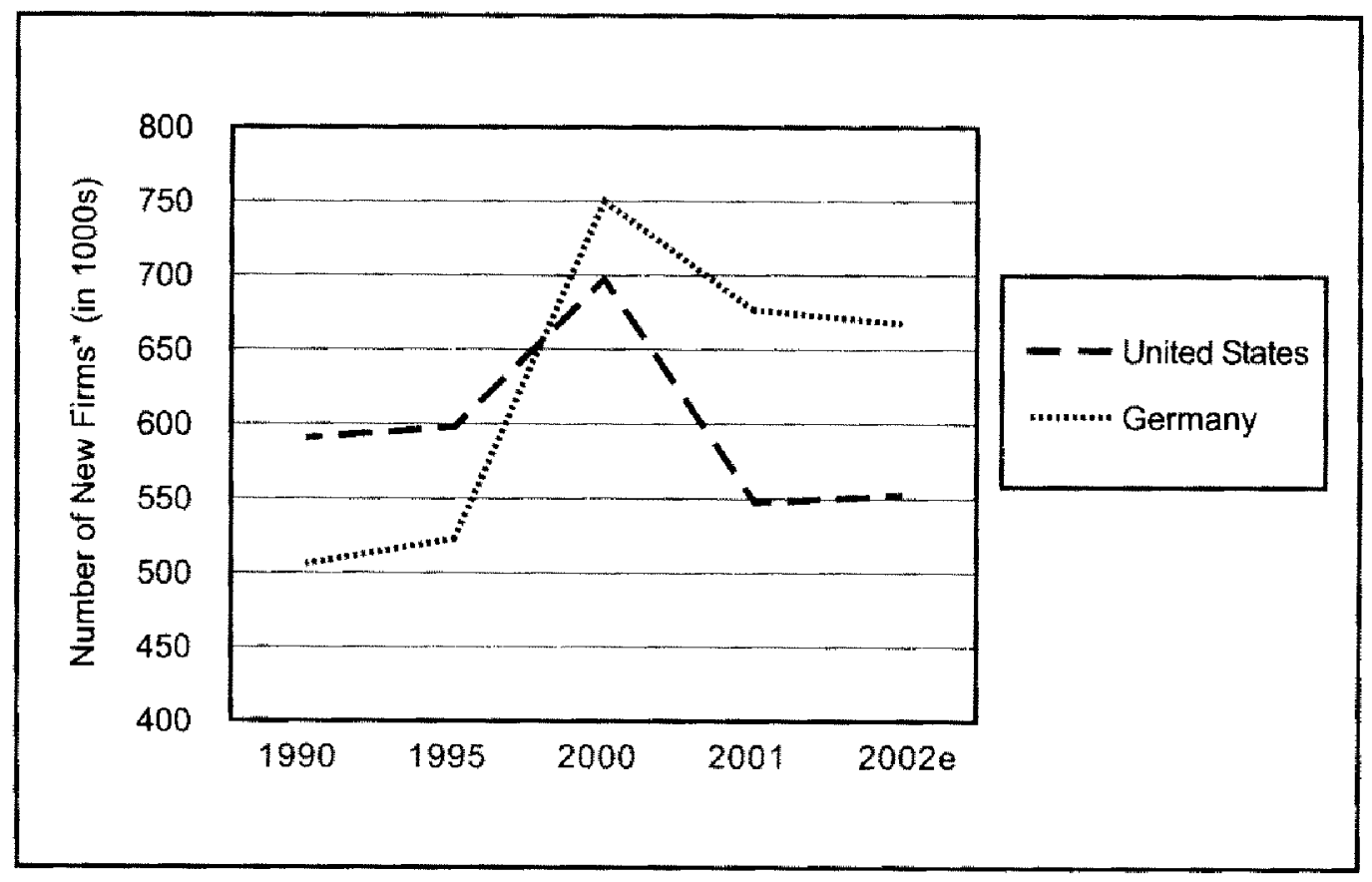

Source: U.S. Small Business Administration; Federal Statistical Office of Germany 


\section{Basic Overview of the Conditions for Small Business Startup in the United States}

The United States has the highest level of entrepreneurial activity in the G7 and within First World countries (Minniti \& Bygrave, 2004). In the United States, the last decades have provided consistency in gross domestic savings at approximately $17 \%$ of GDP, inflation in consumer prices has dropped from approximately $5.4 \%$ in 1990 to $2.19 \%$ in 1999 , real interest rates have remained relatively stable at around $6 \%$ with periods of increases and decreases, GDP per capita rose from $\$ 23,000$ to approximately $\$ 32,000$, and unemployment dropped over the 1990 s until the fallout from the technology sector losses and the aftermath of the September 11, 2001 attacks (World Bank / International Bank for Reconstruction and Development, 2001). Aside from the challenges of the technology slump and the terrorist attacks in 2001, the economic and social settings have been relatively stable. Attention to small business development has been a longstanding area of focus with the Small Business Administration getting its start as early as 1932 but officially beginning to offer service in 1953 , since which time it has helped more than 20 million people start and grow businesses and offered more than $\$ 170$ billion in loans, grants, or other programs to these individuals. According to the U.S. Small Business Administration (Small Business Administration Office of Advocacy, 2003), small businesses represented more than $99.7 \%$ of all employers (less than 500 employees) in the United States in 2002 and provided more than $50 \%$ of the nonfarm GDP in the United States, employed over fifty percent of all private sector employees, and totaled approximately 22.9 million businesses overall in 2002. New business start up of employer firms (those employing more than one person) in the United States had strong periods of growth in the $1990 \mathrm{~s}$, but growth in this sector slowed in the 2000s, as shown in Figure 2. However, it is important to note that sole proprietorships are not reported in this data, and they represent approximately two times the number of enterprises as do employer firms in the United States (Small Business Administration, 2003).

\section{Basic Overview of the Conditions for Small Business Startup in Germany}

In Germany, the period beginning in 1990 was fraught with social change, the most important of which was the reunification of the former East Germany with West Germany. Vast sums of money were used to support the reunification effort and to enable economic development and infrastructure support to the new states in the eastern part of the reunited country. Large increases were made in taxes paid by West Germans to fund infrastructure development, and economic improvements were centered on the eastern states in an effort to raise salaries, deal with an unemployment rate at least twice that of the western states, and to buffer economic productivity. At the same time, during that decade, the country's overall unemployment rate raised from $6 \%$ to $9.7 \%$, real interest rates stayed stable at around $8 \%$, consumer price inflation was reduced, gross domestic savings stayed stable at approximately $23 \%$, and GDP per capita grew from $\$ 19,000$ to over $\$ 23,000$ (World Bank / International Bank for Reconstruction and Development, 
2001). At the same time, the "Mittelstand" sector of the economy, which includes small and medium sized enterprises, consisted of 3.2 million enterprises in 1999, represented $99.3 \%$ of all enterprises subject to VAT (Value Added Tax payments), and employed 20 million people (Hauser, 2000). As Figure 2 demonstrates, the number of new business registrations in Germany increased much over the 1990 s, reflecting an increasing trend toward entrepreneurial activity in both the former East Germany and the Western states. However, the increasing shift to entrepreneurial development in Germany has not yet been mirrored in the way in which early stage venture capital investment funds are being spent in the two countries though. According to EUROSTAT (EUROSTAT 2003), between 2-3 times the percentage of GDP is spent in early stage venture capital investment in the United States than in Germany. In his evaluation of the state of small and medium enterprises in Germany in 2000, Hauser (2000: 14-15) notes, “...the entrepreneurial spirit in the overall population has been invigorated and ... an increasing number of people nowadays is prepared to take on the risks and opportunities of self-employment... During the first years after the reunification, the number of self-employed has increased more rapidly in the New Federal States than in the old ones.... But in the following years the number of newly established businesses, starting from a very high level, has been decreasing."

As a result of the differing social and economic conditions in place in each country over the last fifteen years, it was anticipated that the students who had grown up in these settings would have different self-perceptions about entrepreneurial orientation as well as different perceptions about the entrepreneurial orientation of their countrymen.

Hypothesis 3: Individuals from countries with less volatile economic and social conditions will have a higher self-perception of their entrepreneurial orientation and a higher perception of the entrepreneurial orientations of their countrymen.

\section{Methods}

The survey was designed as a part of a cross-national summer school project involving students from two institutions, a University of Applied Sciences in Germany and a comprehensive liberal arts university in the Southeastern United States. Students studying business administration topics at both institutions were administered the survey. Surveys were administered in English only, after piloting the survey with English-speaking German students majoring in business studies at the University of Applied Sciences indicated acceptable understanding of all terms and requirements of the surveys. Surveys were done as a part of an English class assignment for the business students in Germany ( $\mathrm{n}=100$ students), and as a part of several sections of management courses in the United States $(n=$ 177 students), resulting in a total sample of 277 . The German students involved in the study had already had several years of English language study and were 
completing some of their respective university course work in English as well. Three of the students from the German institution and 35 of the students from the U.S. institution were not citizens from the country in which the respective educational institution was located. To enable the comparison of perceptions of entrepreneurial orientation based on country-specific social and economic issues, these students were eliminated from the analysis, and therefore, the remaining sample $(n=242)$ included 95 German students studying at the University of Applied Sciences in Germany and 147 U.S. students studying at the liberal arts university in the Southeastern U.S.

The scale used to assess entrepreneurial orientation was taken from Grant and Bush (1995) and adapted to also enable the capture of students' perceptions of the level of entrepreneurial orientation of their countrymen. As this scale was originally developed with the use of a student sample, this was not deemed problematic. In addition, as the scale was developed to test student perceptions of entrepreneurial orientation, the exploratory extension to using it within the context of identifying student perceptions of countrymen's entrepreneurial orientations was not deemed problematic, though all of the standard factor structure and reliability analyses were done and reported for each scale separately in this extension. The scale asked respondents to identify the extent to which they were more or less likely to act in a particular manner with respect to 6 core behaviors: seek creative ways to solve problems, challenge others to explore new ways of thinking, look for new ways of dealing with routine situations, demonstrate persistence in efforts to influence change, seek unusual or novel solutions to problems, and continue efforts to change things even when others claim the "old" way of doing things is better. We used this scale to measure Self-Perceptions of Entrepreneurial Orientation by asking respondents, "Relative to most people you know, are you more or less likely to ..." with each of the behaviors. We also used this scale to measure Perceptions of Countrymen's Entrepreneurial Orientation, by asking respondents, "On average, most people in my home country are more or less likely to..." with each of the behaviors. In both cases the scales were assessed, as in Grant and Bush (1995) on a six-point scale. In this way, we were able to assess both the student's own perceptions about his/her own behavior, as well as the student's perceptions of how strong the entrepreneurial orientation is among his/her countrymen.

Grant and Bush (1995) found acceptable reliability of the scale instrument $(\alpha=.80)$ and a single factor which accounted for $46.8 \%$ of the variability in the six items. We evaluated reliability for each group (German and US) separately as well as a combined reliability measure. In our evaluation of the reliability of the instrument for measuring Self-Perceptions of Entrepreneurial Orientation, we found reliability acceptable for Germany $(\alpha=.76)$, the United States $(\alpha=.90)$ and the combined group $(\alpha=.87)$. In evaluating the reliability of the instrument for measuring Perceptions of Countrymen's Entrepreneurial Orientation, we also found acceptable reliability for all three ( $\alpha=.84$ for the Germans; $\alpha=.93$ for the United States; and $\alpha=.90$ for the combined group). 
Principal components analysis was done for both scales to identify if they were unidimensional, as noted in previous work. Factor analysis for the Self-Perceptions of Entrepreneurial Orientation scale indicated one factor, with an eigenvalue of 3.67 and variance explained of $60.94 \%$, with commonalities ranging from $.43-.68$ for the combined groups on self-perceptions of entrepreneurial orientation. Individual factor analyses were completed for each subgroup, and both yielded one factor each, though the commonalities were rather low for one of the items in the German sample. Factor analysis was also completed for the Perceptions of Countrymen's Entrepreneurial Orientation. One factor resulted with an eigenvalue of 4.101 , explaining $68.35 \%$ of the variance, with commonalities ranging from $.50-.75$. Factor analysis was also completed for each of the subgroups with similar findings.

Parents' Business Status was assessed with five choices including neither parent had his or her own business, father had his own business, mother had her own business, each of the parents had his or her own business, and both parents worked together in their own business. For data analysis purposes, these alternatives were compressed to provide a dichotomous variable with 0 indicating that neither parent was involved in their own business and 1 indicating that at least one was involved in his or her own business. Further operationalizations of the data were the coding of Gender ( 0 if a male and 1 if a female) and Country ( 1 for Germany and 2 for the United States).

Table 1

Descriptives and Correlations

\begin{tabular}{l|c|c|c|c|c|c|c}
\hline Variable & Mean & s.d. & \multicolumn{5}{|c}{ Correlations } \\
\hline 1. Age & 23.4 & 3.18 & & & & & \\
2. Country & 1.60 & .49 & $-.09 \ddagger$ & & & & \\
3. Gender & .4 & .49 & -.02 & $.11^{*}$ & & & \\
4. Parents Have Own Business? & .38 & .49 & $.11^{*}$ & .03 & -.05 & & \\
5. Perception of Country & & & & & & & \\
Entrepreneurial Orientation & 15.91 & 6.08 & .07 & $.14^{*}$ & $.09 a$ & .03 & \\
6. Self-Perception of & & & & & & & \\
Entrepreneurial Orientation & 18.91 & 5.65 & $.11^{*}$ & $.10 \ddagger$ & .06 & $.17^{\star *}$ & $.26^{* *}$ \\
\hline
\end{tabular}

$\ddagger p=.10 \quad * p=.05 \quad * * p=.01 \quad n=242$ 
Table 2

Regression Results

\begin{tabular}{|c|c|c|c|c|c|c|}
\hline \multirow{2}{*}{$\begin{array}{l}\text { Variable } \\
\text { Age }\end{array}$} & \multicolumn{3}{|c|}{$\begin{array}{c}\text { Self-Perceptions of } \\
\text { Entrepreneurial Orientation }\end{array}$} & \multicolumn{3}{|c|}{$\begin{array}{l}\text { Perceptions of Countrymen's } \\
\text { Entrepreneurial Orientation }\end{array}$} \\
\hline & $.198 \ddagger$ & $.233^{*}$ & $.252^{*}$ & .130 & .136 & .163 \\
\hline Gender & .656 & .562 & .43 & 1.098 & 1.082 & .901 \\
\hline $\begin{array}{l}\text { Parents' } \\
\text { Business } \\
\text { Status }\end{array}$ & $2.084^{* *}$ & $2.157^{\star \star}$ & .356 & .456 & & \\
\hline Country & $1.292 \ddagger$ & $1.765^{\star}$ & & & & \\
\hline $\mathrm{F}$ & 1.895 & $3.975^{* *}$ & $3.788^{* *}$ & 1.501 & 1.062 & $2.033 \ddagger$ \\
\hline $\begin{array}{l}\text { R2 / Sign. } \\
\text { F Change }\end{array}$ & .124 & $.218 / 8.023^{k *}$ & $.244 / 3.122 \ddagger$ & .111 & $.114 ! .196$ & $.181 / 4.895^{*}$ \\
\hline
\end{tabular}

$\ddagger p=.10 \quad{ }^{*} p=.05 \quad{ }^{* *} p=.01 \quad n=242$

Data analysis consisted of completing regression with age and gender in the first step, and then adding in subsequent steps Parents' Business Status, and Country for regressing each of the dependent variables of Self-Perceptions of Entrepreneurial Orientation and Perceptions of Countrymen's Entrepreneurial Orientation. Descriptive statistics and correlations are provided in Table 1.

\section{Results}

Inspection of Table 1 indicated that Self-Perception of Entrepreneurial Orientation was positively and significantly correlated with Age $(\mathrm{p}<.05)$, indicating a potential maturational effect (Inglehart \& Baker, 2000). Moreover, Country of citizenship was associated with both Perception of Countrymen's Entrepreneurial Orientation $(p<.05)$ and Self-Perception of Entrepreneurial Orientation $(p<.10)$. Parent's Business Status was associated with Self-Perception of Entrepreneurial Orientation $(r=-.17 ; p<.01)$. Further, Gender was only associated with Perceptions of Countrymen's Entrepreneurial Orientation $(\mathrm{p}<.10)$.

In reviewing the results of the regression analysis in Table 2 , the results indicate no support for Hypothesis 1, which suggested that females would score lower on entrepreneurial orientation than would males. Perhaps the lack of specificity in the wording of the scale prompted the finding that was different from previous studies. However, another explanation may be that these males and females had self-selected into the respective business field of study and were already similarly challenged with needs for risk taking and innovation.

Results indicated partial support for Hypothesis 2, which suggested that those students who have parents with their own business will have higher levels of 
entrepreneurial orientation than will those students whose parents are not so engaged $(\mathrm{p}<.05)$. However, there was no significant difference on evaluation of countrymen's entrepreneurial orientation $(p>.10)$. Further analysis indicated no significant differences on these perceptions based on whether the students' father or mother had his or her own business, or whether the parents each had their own businesses or operated a business together, and there was no significant difference in female students' self-perceptions of EO scores based on which parent had a business.

Finally, results indicated support for Hypothesis 3 that self-perceptions of entrepreneurial orientation $(p<.10)$ and perceptions of countrymen's entrepreneurial orientations $(\mathrm{p}<.05)$ will differ by social and economic settings with the students from the U.S. reporting higher scores on both measures than students from Germany.

\section{Discussion}

This paper has broadened the consideration of entrepreneurial orientation by creating parallel measures of self-perception and perceptions of countrymen's entrepreneurial orientation. In addition, we have attempted to extend the assessment of entrepreneurial orientation by including different economic and social settings within which business students have been socialized. The results provide preliminary insight into the need for further consideration of the effects of different social, economic, and cultural settings on the development of entrepreneurial orientation.

Future research will need to explore the construct of entrepreneurial orientation as well as to include measures of entrepreneurial intention to further identify potential outcomes of orientations. More work is also needed to identify the specific social and economic indicators that contribute to increased entrepreneurial orientation of young people and future business leaders. Moreover, further attention may also be directed to exploring the nature of the relationship between parental involvement in entrepreneurship and effects on their children's interest and involvement in entrepreneurial activity of their own.

The limitations of the study include a focus on only one institution from each country, which may not be representative of all institutions in the respective countries (Tung, 2008). The study also employs a rather conservative sample size, but this is not unique as many cross-national samples rely on small sample size (e.g., Preston, Karahanna, and Rowe (2006) compared information sharing among CIOs in the U.S. $(n=163)$ and France $(n=44)$; Kickul, Lester, and Belgio (2004) compared the perceptions of the psychological contract between U.S. $(n=60)$ and Hong Kong Chinese $(n=76)$; and Lee, Yang, and Graham (2006) studied total of 176 Chinese and U.S. executives to compare tension in buyer seller interactions.) Furthermore, the questions asking about entrepreneurial orientation were loosely tied to specific entrepreneurial activity, and more directed statements should be formalized to assure common interpretation of the 
construct. All respondents were required to answer the survey questionnaire in English. Also, since Harzing (2005) notes that when English-language instruments are administered to non-native speakers, there is a tendency for results to more mirror those of native speakers, it would be helpful to evaluate and compare the differences in results for such instruments and outcomes when administered in native languages. Finally, it would probably be helpful in future studies to include formal cultural, economic, and social indicators measures to use that as a control rather than country by itself.

Despite these limitations, this study demonstrates a tentative and exploratory step to uncover the differences in perception about risk taking behavior among business students, and potentially future business leaders, in Germany and the United States. If such differences exist among well developed nations that are somewhat similar on cultural values (Hofstede, 2001), then this work supports further the call of Lee-Ross and Mitchell (2007) in arguing for further development of the issues that contribute to differences in entrepreneurial orientation as a precursor to entrepreneurial activity.

\section{References}

Aldrich II, B., \& Martinez, M. A. (2001). Many are called, but few are chosen: An evolutionary perspective for the study of entrepreneurship. Entrepreneurship Theory and Practice, 25(4), 41-57.

Avlonitis, G., \& Salavou, H. (2007, May). Entrepreneurial orientation of SMEs, product innovativeness, and performance. Journal of Business Research, 60(5), 566-575.

Baumeister, R. F, \& Muraven, M. (1996). Identity as adaptation to social, cultural, and historical context. Journal of Adolescence, 19, 405- 416.

Bird, B. (1988). Implementing entrepreneurial ideas: The case for intention. Academy of Management Review, 13, 442-453.

Bloodgood, H. M., Sapienza, H. J., \& Carsrud, A. L. (1995). The dynamics of new business startups: Person, context, and process. In J. A. Katz \& R. H. Brockhaus (Eds.), Advances in entrepreneurship, firm emergence, and growth. Vol. 2. Stamford, CT: JAI Press, 123-144.

Brush, C. (1997). Women-owned businesses: Obstacles and opportunities. Journal of Developmental Entrepreneurship, 2(1), 1-24.

Burgelman, R. A. (1983). A process model of internal corporate venturing in the diversified major firm. Administrative Science Quarterly, 28, 223-244.

Covin, J. G., \& Slevin, D. P. (1989). Strategic management of small firms in hostile and benign environments. Strategic Management Journal, 10, 75-87. 
Davidsson. P., \& Honig, B. (2003). The role of social and human capital among nascent entrepreneurs. Journal of Business Venturing, 18(3), 101-23.

EUROSTAT. The European Commission. (2003). Retrieved September 12, 2003, from http//europa.eu.int/comm/eurostat/Public/datashop/print-product/EN?catalogue=Eur ostat\&product $=1-$ ir061-EN\&mode $=$ download.

Federal Statistical Office of Germany. (2003). Retrieved September 5, 2003, from http:// www.destatis.de/basis/e/fist/fisttab011.htm.

Grant, E. S, \& Bush, A. J. (1995). Entrepreneurial orientation in the salesforce: Development of the EOS Measture. Proceedings of the Southern Marketing Association, November 8-11, 1995. Retrieved April 4, 2003, from http:/www.sbaer.uca,edu/Research/1995/SMA/95swa132.htm.

Grant, J. M. (1996). The proactive personality scale as a predictor of entrepreneurial intentions. Journal of Small Business Management. 34(3), 42-50.

Gundelach, P. (1994). National value differences: Modernization or institutionalization? International Journal of Comparative Sociology, 35(1-2), 37-58.

Harzing, A. (2005, August). Does the use of English-language questionnaires in cross-national research obscure national differences? International Journal of Cross Cultural Management, 5(2), 213-224.

Hauser, H.-E. (2000). SMEs in Germany: Facts and figures. Institut für Mittelstandsforschung Bonn. Retrieved September 3, 2003, from http:/www.ifm-bonn.de/ergebnis/ sme.htm.

Hersch, J. (1996). Smoking, seat belts and other risky consumer decisions: Differences by gender and race. Managerial and Decision Economics, September, 471-81.

Hofstede, G. 2001. Culture s consequences: Comparing values, behaviors, institutions, and organizations across nations. Second Edition. Thousand Oaks, CA: Sage.

Hughes, M., \& Morgan, R. (2007, July). Deconstructing the relationship between entrepreneurial orientation and business performance at the embryonic stage of firm growth. Industrial Marketing Management, 36(5), 651-661.

Inglehart, R. (1995). Changing values, economic development and political change, International Social Science Joumal, 47, 379-403.

Inglehart, R., \& Baker, W. E. (2000). Modernization, cultural change, and the persistence of traditional values. American Sociological Review, 65, 19-51.

Jiankoplos, N. A., \& Bernasek, A. (1998). Are women more risk averse? Economic Inquiry, 36(4), 620-631. 
Kickul, J., Lester, S., \& Belgio, E. (2004, August). Attitudinal and behavioral outcomes of psychological contract breach: A cross-cultural comparison of the United States and Hong Kong Chinese. Internationat Journal of Cross Cultural Management, 4(2), 229-252.

Krueger, N. F. (1993). The impact of prior entrepreneurial exposure on perceptions of new venture feasibility and desirability. Entrepreneurship Theory and Practice, I8(1), $5-21$.

Langowitz, N., Sharpe, N., \& Godwyn, M. (2006). Women's business centers in the United States: Effective entrepreneurship training and policy implementation. Journal of Small Business \& Entrepreneurship, 19(2), 167-181.

Lee, K., Yang, G., \& Graham, J. (2006, September). Tension and trust in international business negotiations: American executives negotiating with Chinese executives. Journal of International Business Studies, 37(5), 623-641.

Lee, S. M., \& Peterson, S. J. (2000). Culture, entrepreneurial orientation, and global competitiveness. Journal of World Business, 35(4), 401-416.

Lee-Ross, D., \& Mitchell, B. (2007, June). Doing business in the Torres Straits: A study of the relationship between culture and the nature of indigenous entrepreneurs. Joumal of Developmental Entrepreneurship, 12(2), 199-216.

Lumpkin, G. T., \& Dess, G. G. (1996). Clarifying the entrepreneurial orientation construct and linking it to performance. Academy of Management Review, 21(1), 135-172.

Lyon, D. W., Lumpkin, G. T., \& Dess, G. G. (2000). Enhancing entrepreneurial orientation research: Operationalizing and measuring a key strategic decision making process. Journal of Management, 26(5), 1055-1085.

Miller, D. (1983). The correlates of entrepreneurship in three types of firms. Management Science, 29, 770-791.

Minniti. M., \& Bygrave, W. (2004). GEM Global Entrepreneurship Monitor: National Entrepreneurship Assessment. United States of America. 2003 Executive Report. Babson Park, MA: Babson College.

Morris, M. H., \& Paul, G. W. (1987). The relationship between entrepreneurship and marketing in established firms. Journal of Business Venturing, 2(3), 247-259.

Parks-Yancy, R., DiTomaso, N., \& Post, C. (2005, August). The effects of social capital resources on the careers of gender and class groups. In: Gender and Diversity in Organizations Conference Paper Abstracts. (2005). Academy of Management Proceedings, Academy of Management, New York. 
Preston, D., Karahanna, E., \& Rowe, F. (2006, May). Development of shared understanding between the chief information officer and top management team in U.S. and French organizations: A cross-cultural comparison. IEEE Transactions on Engineering Management, 53(2), 191-206.

Rokeach, M. (1973). The Nature of Human Values. New York: Free Press.

Scott, M. G., \& Twomey, D. F. (1988). The long-term supply of entrepreneurs: Students' career aspirations in relation to entrepreneurship. Journal of Small Business Management, 26(October), 37-44.

Small Business Administration Office of Advocacy. (2003, May). Small Business by the Numbers. Washington: U.S. Small Business Administration.

Trump, T. M. (1991). Value formation and postmaterialism: Inglehart's theory of value change reconsidered. Comparative Political Studies, 24(3), 365-390.

Tung, R. (2008, January). The cross-cultural research imperative: The need to balance cross-national and intra-national diversity. Journal of International Business Studies, $39(1), 41-46$.

Van Lange, P. A. M., De Bruin, E. M. N., Otten, W., \& Joireman, J. A. (1997). Development of prosocial, individualistic, and competitive orientations: Theory and preliminary evidence. Joumal of Personality and Social Psychology, 73(4), 733-746.

Wagner. J., \& Stemberg, R. (2004). Start-up activities, individual characteristics, and the regional milieu: Lessons for entrepreneurship support policies from German micro data. The Annals of Regional Science 38(2), 219-39.

West, G., Bamford, C., \& J. Marsden (2008, January). Contrasting entrepreneurial economic development in emerging Latin American economies: Applications and extensions of resource-based theory. Entrepreneurship: Theory \& Practice, 32(1), 15-36.

World Bank/nternational Bank for Reconstruction and Development. (2001). World Development Indicators. Program. Win-Stars. V4.2 CD-ROM.

Darla Domke-Damonte, Ph.D., is Assistant Dean of International Programs at the E. Craig Wall College of Business Administration at Coastal Carolina University (USA).

Jens Andreas Faulstich, M.A., is Deputy Director of Languages and International Affairs at the Fachhochschule Koblenz RheinAhr Campus (Germany).

William Woodson III was formerly the Director of the Wall Fellows Program at Coastal Carolina University (USA). He is now in independent law practice. 